\title{
Automation and Robotization of Underground Mining in Poland
}

\author{
Eukasz Bołoz $^{1, * \mathbb{D} \text { and Witold Biały }}{ }^{2}$ \\ 1 Department of Machinery Engineering and Transport, Faculty of Mechanical Engineering and Robotics, \\ AGH University of Science and Technology, A. Mickiewicza Av. 30, 30-059 Krakow, Poland \\ 2 Department of Production Engineering, Faculty of Management and Organization, \\ Silesian University of Technology, Roosevelta 26, 44-800 Zabrze, Poland; witold.bialy@polsl.pl \\ * Correspondence: boloz@agh.edu.pl; Tel.: +48-12-617-30-81
}

Received: 11 August 2020; Accepted: 21 September 2020; Published: 16 October 2020

\begin{abstract}
The article concerns the condition of automation and robotization of underground mining in Poland. Attention has been focused on the specific character of the mining industry. This limits the possibility of using robotization, and sometimes even the mechanization of certain processes. In recent years, robotic and automated machines and machine system solutions have been developed and applied in Poland. They are autonomous to a various degree, depending on the branch. The type of automation and artificial intelligence depends on the specific use. Some examples presently being used include the MIKRUS automated longwall system and autonomous device(s) for breaking rocks or mining rescue work. In Poland, fully automated plow systems produced by foreign companies are also used. Companies in Poland and international research centers are also actively engaged in the development of underwater and space mining. where robotization is of key importance. Research is also being undertaken by Robotics in Mining, euRobotics and PERASPERA as well as Space Mining Conference.
\end{abstract}

Keywords: underground robots; automation in mines; remote control; autonomous underground machinery

\section{Introduction}

Underground mining exploits various useful minerals. The exploitation and transport of minerals are mostly mechanized. Some machines are automated and, to varying degrees, autonomous [1,2]. In Poland, the largest market for underground mining machinery is the mining of hard coal. This is followed by mining for copper ores and other raw materials, such as rock salt or zinc and lead ores. The share of mining for these other raw materials is small. Difficult conditions of machine operation have resulted in noticeable changes in the approach to safety and comfort at work. This is the reason for seeking a method to eliminate or reduce human participation in mining operations. The progress in mobile control and navigation techniques has led to an interest in automation and robotization. Measurable economic benefits have been obtained by using such solutions. Another important consideration is increasing the safety and comfort of underground workers. Robotization can contribute to enhanced safety when withdrawing people from the most threatened zones. These zones are where mining usually takes place. A separate and increasing need is using robots in underground rescue operations [3].

Coal mines are difficult workplaces, not only for humans, but also for machines. Natural hazards, limited space, a lack of natural light, dustiness, humidity, high temperature and mine atmosphere hinder mechanization. Despite these adversities, Poland boasts many solutions developed in national 
research centers in cooperation with machine manufacturers. The state of underground mining automation and robotization in Poland will be presented through several selected examples.

\section{Solutions Applied to Mining in Poland}

In Poland, various solutions for mining machines and machine systems with varying degrees of autonomy are designed and manufactured. Several such examples will be briefly described.

\subsection{MIKRUS Automated Longwall System}

Raw materials found in coal seams are exploited by means of mechanized longwall systems [4]. Longwall systems are systems of compatible and cooperating machines that simultaneously carry out the process of mining (loading and hauling of mined rock) as well as securing the roof. The extraction from ever-thinner seams causes working conditions which make manual control difficult $[5,6]$. Therefore, automated longwall systems need to be developed. The American company Caterpillar Inc. is the leader in the field of automatic plowing systems. Their most advanced product, GH1600, is used by two coal companies in Poland. A competitive longwall technique is the shearer technology, which has been fully automated for use in thin seams. The KOPEX S.A. group (Katowice, Poland) has developed and constructed a longwall system for thin seams. Currently, the solution belongs to the FAMUR S.A group. The system, called MIKRUS ("midget" in Polish), is equipped with a GUŁ-500 (stands for Polish words głowica urabiajaco-ładujaca) cutting and loading head with two cutting drums. GUL-500 is moved by a longwall conveyor along the coal side wall by means of a cable system under the powered roof support units (Figure 1).
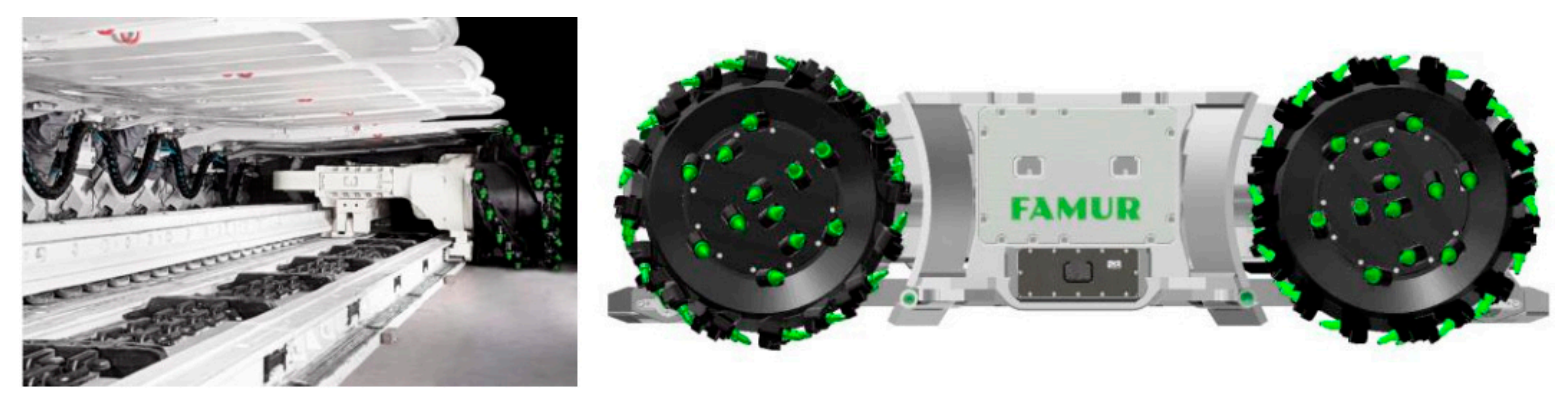

Figure 1. MIKRUS system produced by FAMUR S.A.

The whole complex is powered and controlled by an integrated system located on the surface of the mine (Figure 2). In addition, in the event of a failure, the complex is equipped with a central desktop at the operator's station, which is located in the haulage heading. Trouble-free, automatic and optimal operation is ensured by the EH-WallControl (Elgór + Hansen WallControl) automation system. Information on the work of all longwall face machines is supplied to the automation system. Based on this information, the system generates signals to the control systems of machines (shearer, conveyors, support units, pumps). In the event that information about hazards or pre-emergency conditions appears in individual devices, the system signals it at the operator's workstation. If the permissible operating parameters are exceeded or pre-emergency conditions occur, the system will turn off individual devices or will stop the entire system. For security reasons, the operator can start up individual devices even if there is a risk of failure. Such a status is separately and clearly recorded.

All the data about the operation of longwall equipment are available in particular menus called on the operator's command and are visualized at his workstation. In the automatic work cycle, the operator only controls the speed of the loading cutterhead feed, while the work of other devices is controlled by the master system of the longwall automation complex. The operator can switch over to manual control and change the operating parameters of the devices at any time. The combination of the features of plow and longwall shearer systems in the MIKRUS complex translates into increased operational efficiency in low faces. Moreover, the use of advanced control and diagnostic systems has 
enabled the construction of a fully automated longwall complex. The MIKRUS longwall system for mining thin seams is a unique solution on a global scale. The MIKRUS longwall system allows for profitable and safe extraction in thin coal seams. Innovative solutions based on automation contribute to employees' comfort $[7,8]$.
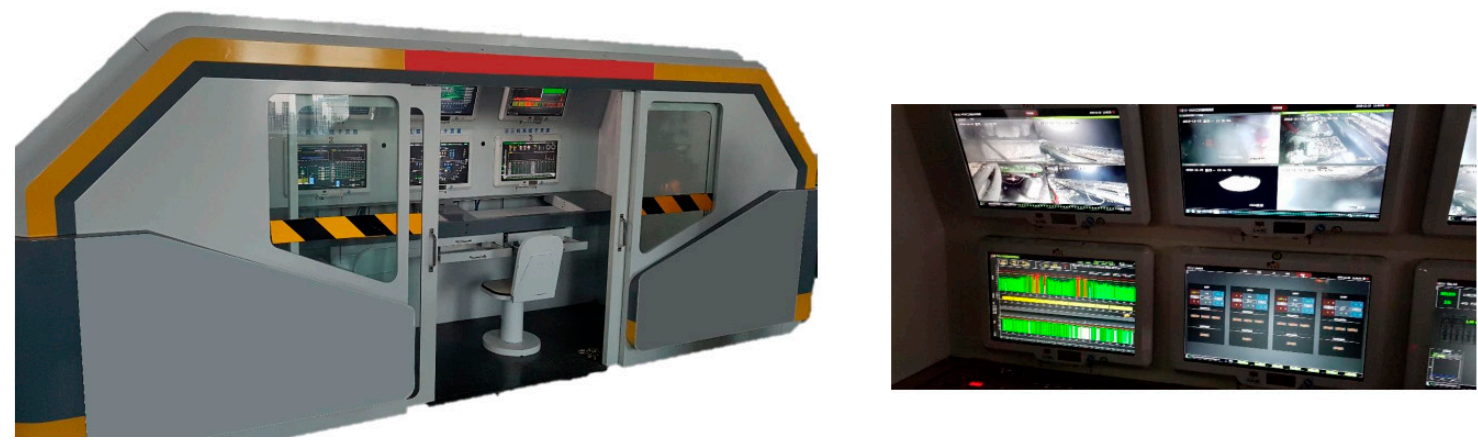

Figure 2. Cabin for monitoring the automatic operation of the MIKRUS system from the surface [8].

\subsection{Mine Master Self-Propelled Mining Machines}

In ore mines, such as KGHM Polska Miedź S.A. (Lubin, Poland), the useful mineral is usually mined by means of explosives. Self-propelled drilling machines are used for harsh operating conditions, characterized by an ambient temperature exceeding $35^{\circ}$ Celsius and air humidity up to $98 \%$. The machines are operated at depths ranging from $600 \mathrm{~m}$ to $1200 \mathrm{~m}$, where there are strong saline watercourses, which force the use of subassemblies with high IP 67 (International Protection). In such extreme conditions, the human factor is increasingly often an unreliable element, so a chance to improve work efficiency is seen in the automation and monitoring of mining processes. Mine Master, in cooperation with the AGH University of Science and Technology, based on joint experiences in drilling process automation, designed two modular drilling machine monitoring systems. The system was implemented jointly with the machine user-KGHM Polska Miedź—which works on selected Face Master 1.7 machines [9-11]. Monitoring of drilling machines was first introduced for systems that have a decisive impact on achieving the assumed productivity by machines. In the case of Face Master 1.7 drill rigs, it was a system for monitoring the drilling parameters and drilling frame settings in accordance with the assumed blasting pattern (Figure 3). The natural consequence of monitoring was the implementation of systems for diagnosing the drive system and the hydraulic system of machines. Monitoring has control over the machine, not only during the process of drilling, but also when traveling to and from the workplace on roads with a slope of up to $15^{\circ}$. 


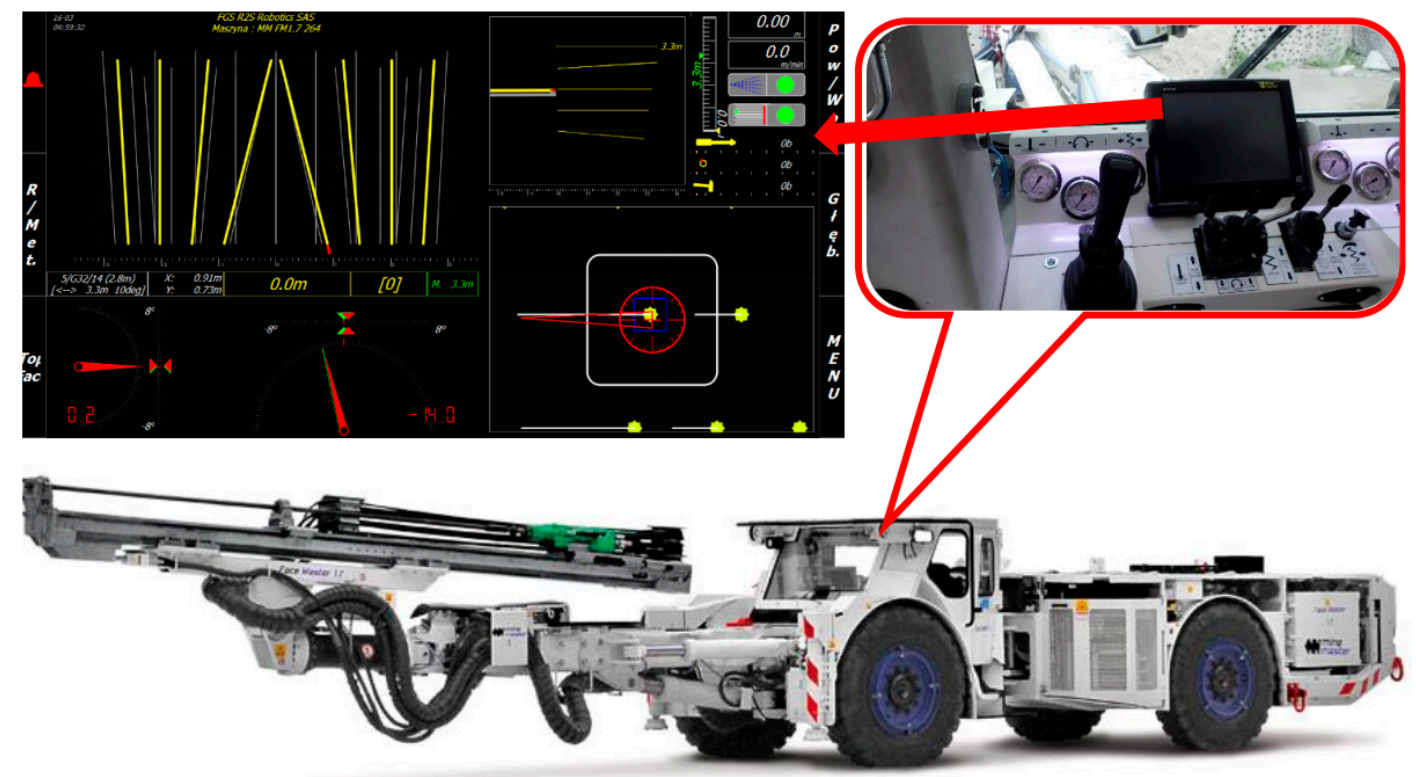

Figure 3. Face Master 1.7 machine with a control panel and a view of the Feeder Guide System (FGS) drill rig positioning system [9].

Monitoring systems for drilling machines used in underground conditions of KGHM Polska Miedź, which successfully completed their tasks, include the following scope:

- Mapping of the blast pattern on the heading face and its visualization on the operator's panel;

- Repeatability of the drilling process in the face geometry;

- Monitoring and control of drilling parameters;

- Quick diagnosis of the drilling system;

- Increased work efficiency;

- $\quad$ Recording of work done;

- USB or WiFi data transfer;

- Generating reports on the work performed (Figure 4);

- Work "in the background" of systems so that their possible failure will not limit the basic functions of the machines;

- Increasing the availability of machines through more precise and faster damage diagnostics.

The FGS system (Feeder Guide System) is the successor of the DMS system (Drilling Monitoring System). DMS monitored only drilling parameters, such as speed, depth or pressure in the hydraulic system.

The basic element of the system is the operator's panel, which contains software that controls the drilling support process. The operator's panel is resistant to operating conditions and has a high-contrast display with built-in function buttons or a touch screen facilitating correct readings. The operator's panel is additionally equipped with an integrated USB port, which enables data transfer. Another element necessary for the proper operation of the FGS system is sensors, the basic task of which is to determine the drill rig's position between the positioning and measuring elements. Thus, it is possible to reflect the position of the drilling frame in the system and the control panel. The software allows employees to create 3D blasting patterns, including the preparation of previous patterns and their uploading via a USB flash drive. The FGS system allows obtaining one plane of the face regardless of the initial state. The length of individual holes is calculated by the system in such a way that they end in one plane. Obtaining this effect with manual control is not possible. The program for creating blasting patterns enables changing the direction of the excavation. The result is the program choosing the appropriate length of the holes. The FGS system in drilling machines has 
contributed to the improvement of drill rigs performance in the area where tests were carried out at Polkowice-Sieroszowice mine, KGHM Polska Miedź S.A. The FGS system has also enhanced work safety for persons staying in the faces. This repeatability in the drilling process results in the proper geometry of the face.

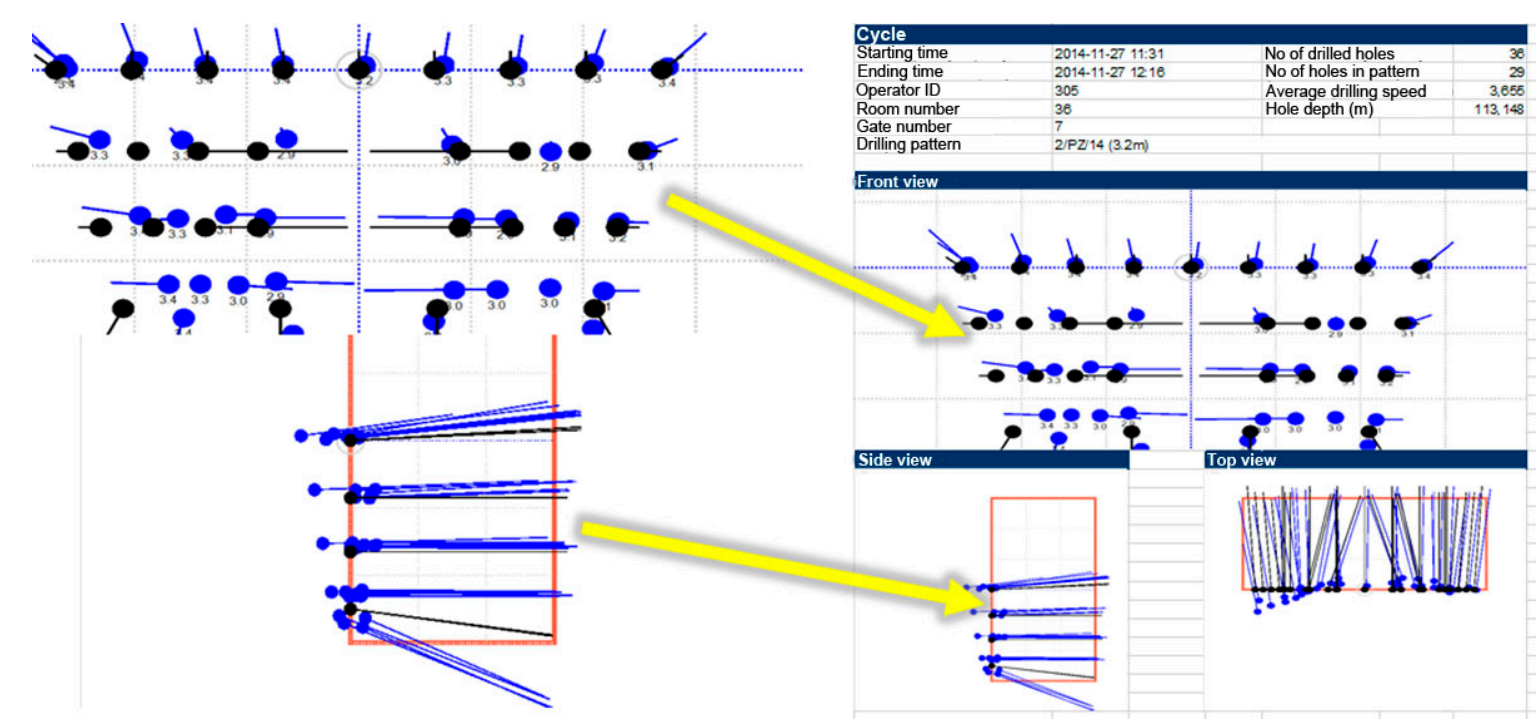

Figure 4. FGS report on drilling with a comparison of the assumed (black) with actually completed blasting pattern (blue) [9].

\subsection{Famur Roadheader}

Making drifts in underground mines is one of the most important processes. In most cases, headings are made with roadheaders controlled locally by the operator. This work is dangerous due to falling rocks, dust, noise and temperature. It was, therefore, decided to withdraw the staff from the area of shearer operation and introduce systems for supervising and automating its work. Elgór-Hanses S.A., which is part of the FAMUR S.A. group(Katowice, Poland), developed and implemented a shearer remote control system. EH-RemoteHeadControl v2 is a system enabling the remote control of roadheaders designed for operation in particularly dangerous zones due to the risk of gas and rock outburst as well as rock burst hazards. The system allows the service staff to work in safe work conditions, as during the shearer operation, they stay in a non-hazardous area. The safety of underground miners is the most important issue of all matters related to the operation of underground mining plants [8].

The system consists of a few elements (Figure 5).

- Up to ca $50 \mathrm{~m}-100 \mathrm{~m}$ behind the shearer, a box with a laser shining parallel to the axis of the excavation is mounted on the roof. The laser position is corrected using a wireless remote control.

- The shearer has a set of devices for automatic positioning of the shearer in the heading. The devices include a set of cameras, sensors and a signal processing controller. A radar is used to communicate with the laser.

- In the safe zone outside the directly threatened area is an operator's workstation in the form of a cage with monitors with a remote-control panel. The operator's workstation is in the form of a cage with monitors and a remote-control panel located in a safe zone outside the directly threatened area.

- Diagnostic of head tools wear [12,13]. 


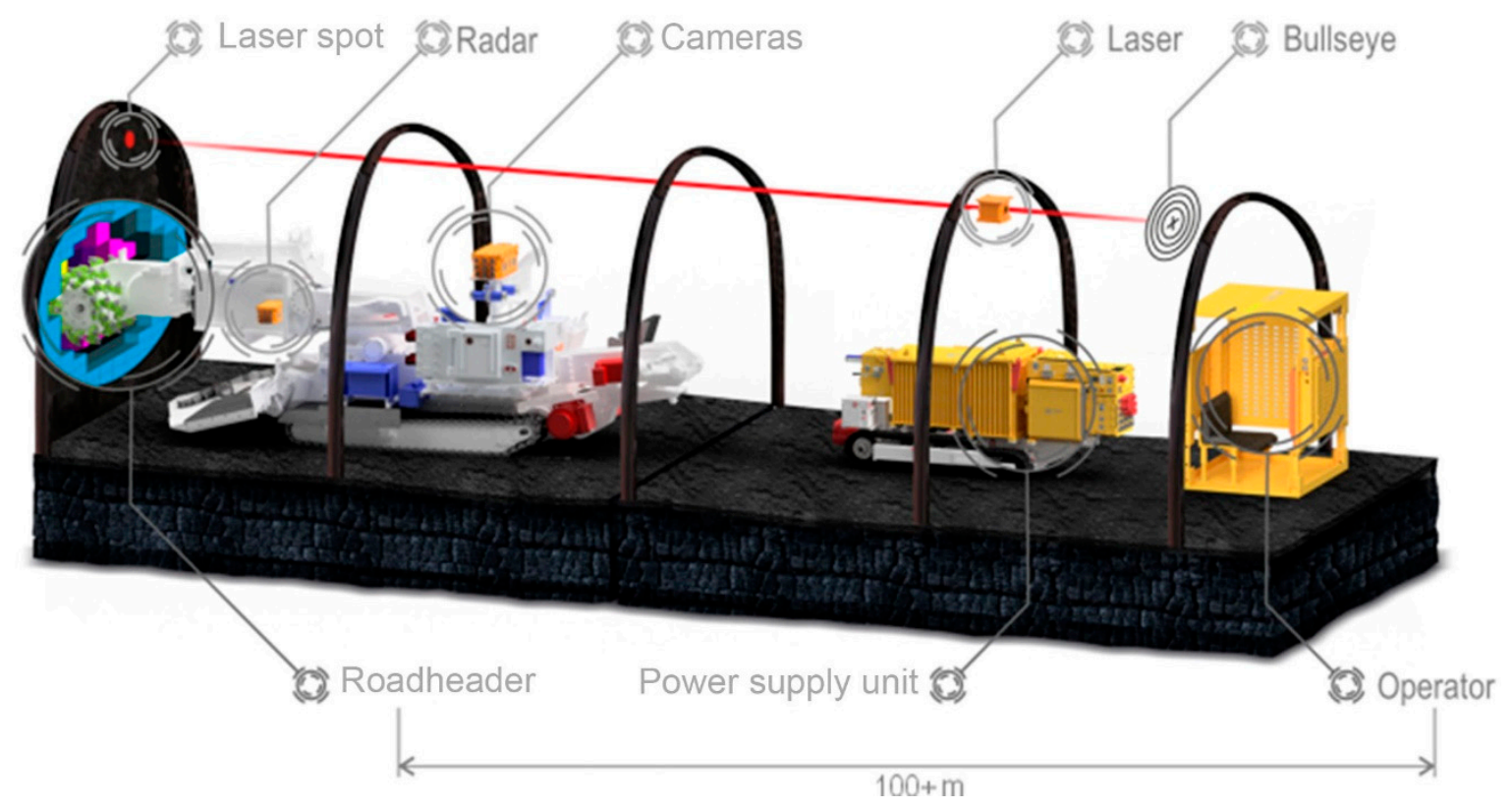

Figure 5. Structure of the EH-RemoteHeadControl v2 system by Elgór + Hansen [8].

The operator's station is equipped with computers presenting diagnostic information and the image from the cameras installed on the shearer as well as visualizing the operation of the machine. The real-time graphic representation of the cutting head makes it easier for the operator to drill the right profile. Audio and video are transmitted from three cameras located in the shearer's surroundings. This allows the operator to better understand the current conditions of the machine. The laser is installed in the excavation every $100 \mathrm{~m}$ and gives a beam of light in two directions. The laser is set using a wireless remote control and/or PC application.

The data recorded by the laser sensor, radar sensor and cameras allow the visualization station to determine the position of the shearer and the head. It also checks the possibility of their movement on an ongoing basis and determining a possible collision. The 3D application additionally maps the state of cutting in the face. It uses various indicators and lights and provides information on the shearer's condition, including the signaling of warnings and emergencies (Figure 6). Data transmission to the surface of the mine enables generating reports on the operation of the system.

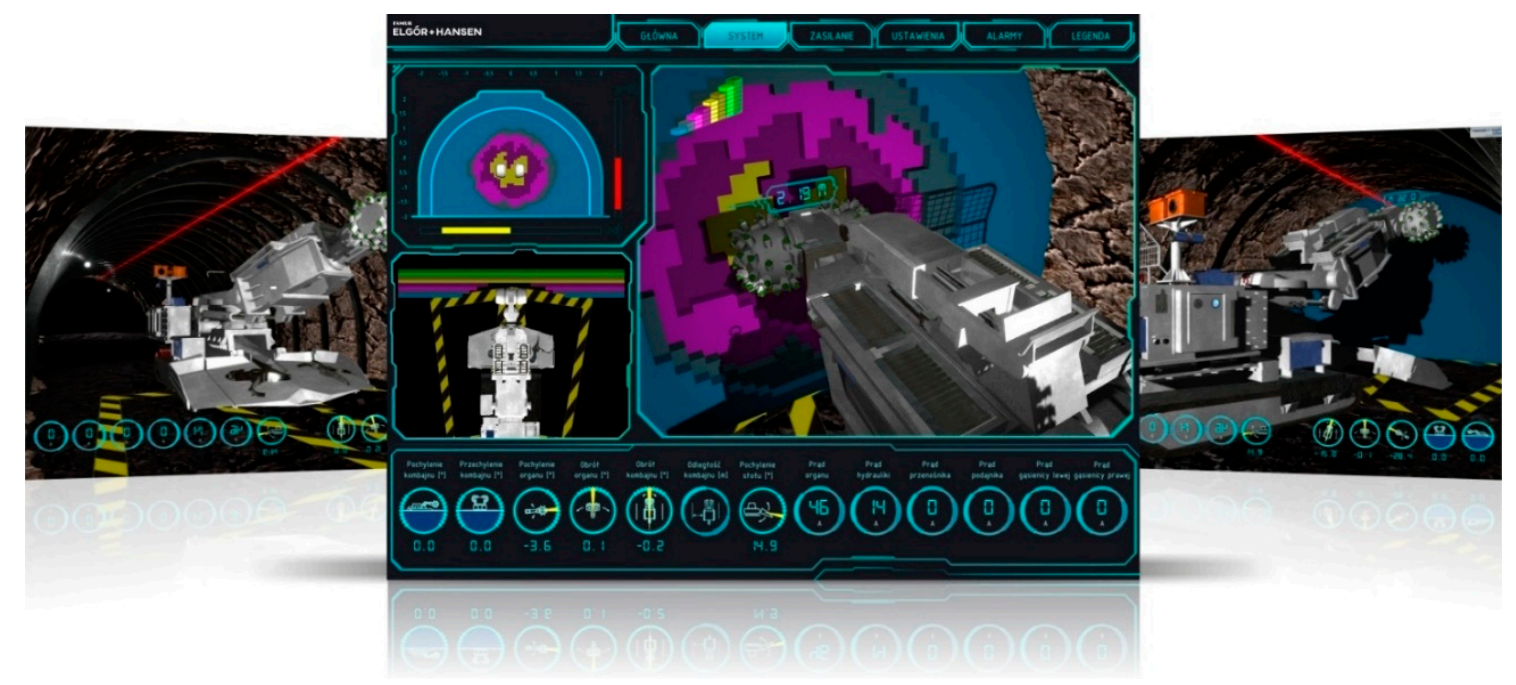

Figure 6. 3D application of the EH-RemoteHeadControl v2 system by Elgór + Hansen. 


\section{Research and Development in the Field of Robotization of Mining in Poland}

Research centers in Poland are engaged in works in the field of mining robotization, which concern not only traditional mining, but also space and underwater mining. The effects of these works have, in most cases, been tested in underground mine conditions, and some of them have already been implemented.

\subsection{Autonomous Machine for Breaking Rocks}

The most important elements of the ore mining process have been presented earlier. In this process, the mined rock from the face is transported to the surface. The transport system includes non-continuous haulage to handling points, also referred to as transfer points, where the mined rock is loaded onto conveyor belts. Large lumps of mined rock can damage the conveyor, so the handling points are fitted with grates mounted by means of manipulators with hydraulic hammers. The operator manipulates the boom to clear the grate of mined rock in the quickest possible way. The operator is exposed to many adverse factors. First, a hammer remote control followed by an autonomous machine were developed and installed. The project was implemented by the consortium composed of KGHM ZANAM S.A., AGH University of Science and Technology and KGHM CUPRUM Sp. z o. o. (Wroclaw, Poland). Research and Development Centre [14-16]. The main goal of the project was to develop an automatic grate cleaning system.

Constructing an autonomous machine required equipping it with an automatic control system, which, based on information from a number of sensors, would react to changes in the environment and generate control signals in such a way that the main goal, i.e., the cleaning of the grate, could be achieved. The main element was a hydraulic boom with a hydraulic hammer attached at the end. The boom has 4 degrees of freedom. An analysis of the functioning of the existing manual system was carried out and consultations with future users of the transfer points were held. The conducted analyses enabled specifying the tasks to be performed by the machine. the most important restrictions and requirements formulated in the form of the following assumptions.

The control system should operate in an autonomous manner.

- The operator can take over control at any time and turn off the autonomous system.

- At least $80 \%$ of activities related to rock crushing will be performed by the machine automatically.

- The operator interfering with the situation on the grate $20 \%$ of the time.

- The process of clearing the grate of mined rock will last up to several minutes.

- Constructional changes must be as small as possible in relation to the existing equipment.

The system is, among other things, equipped with hydraulic cylinder sensors and a mined rock heap scanner. The system was installed at the test stand at KGHM ZANAM S.A. (Figure 7).

The stand was designed and constructed in a manner enabling its use in the underground mines of KGHM Polska Miedź S.A. The device should be adapted to work in the following conditions:

- Relative humidity up to $95 \%$ at a temperature of up to $+40{ }^{\circ} \mathrm{C}$

- Degree of corrosive aggressiveness-C according to PN-71/H-04651

- Maximum relative humidity at a temperature of $+25^{\circ} \mathrm{C}$ or at lower temperatures with $100 \%$ steam condensation. 

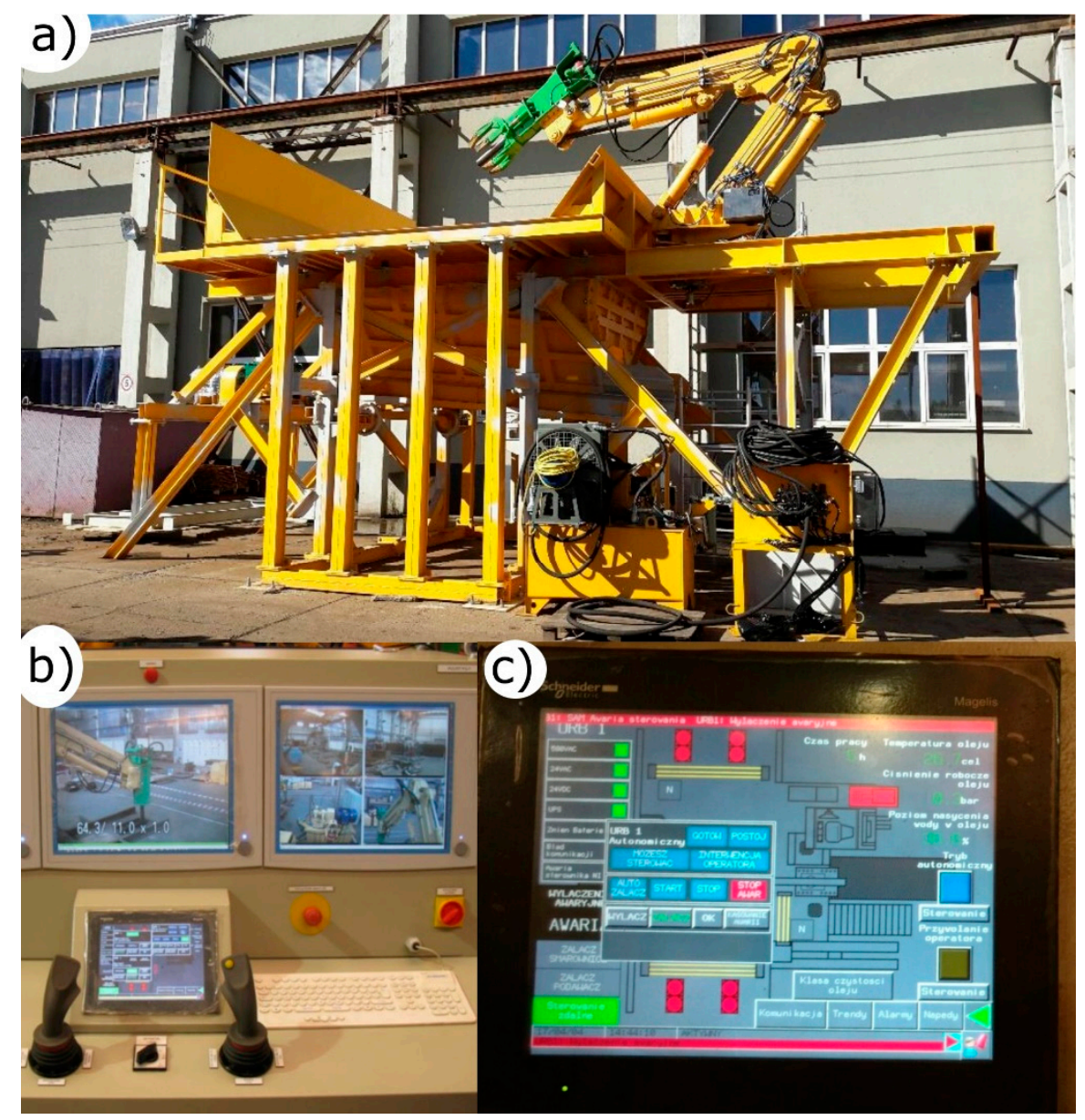

Figure 7. Station for testing; (a) autonomous equipment; (b) operator's panel; (c) GUI (Graphical User Interface) view.

The remote-controlled stand is monitored by cameras. It has been equipped with optical barriers and signaling devices to supervise and ensure traffic safety in the vicinity of the grate. The automation system controls the boom by means of signals determined by the current state of the system and the setpoint. This system consists of a master control layer and a direct control layer. In the superior layer, after identifying the shape and dimensions of the mined rock heap is identified (Figure 8). The control system generates a trajectory that will be implemented by the direct control system. The trajectory was developed using heuristic algorithms and observations of the grate cleaning process. The automatic control system consists of four main modules: mined rock identification, determination of hammer motion trajectory, inverse kinematics and direct control. After being equipped with a shape identification assembly, the device becomes a robot, which autonomously detects the position of mined rock on the grate and, then, starts removing it. 


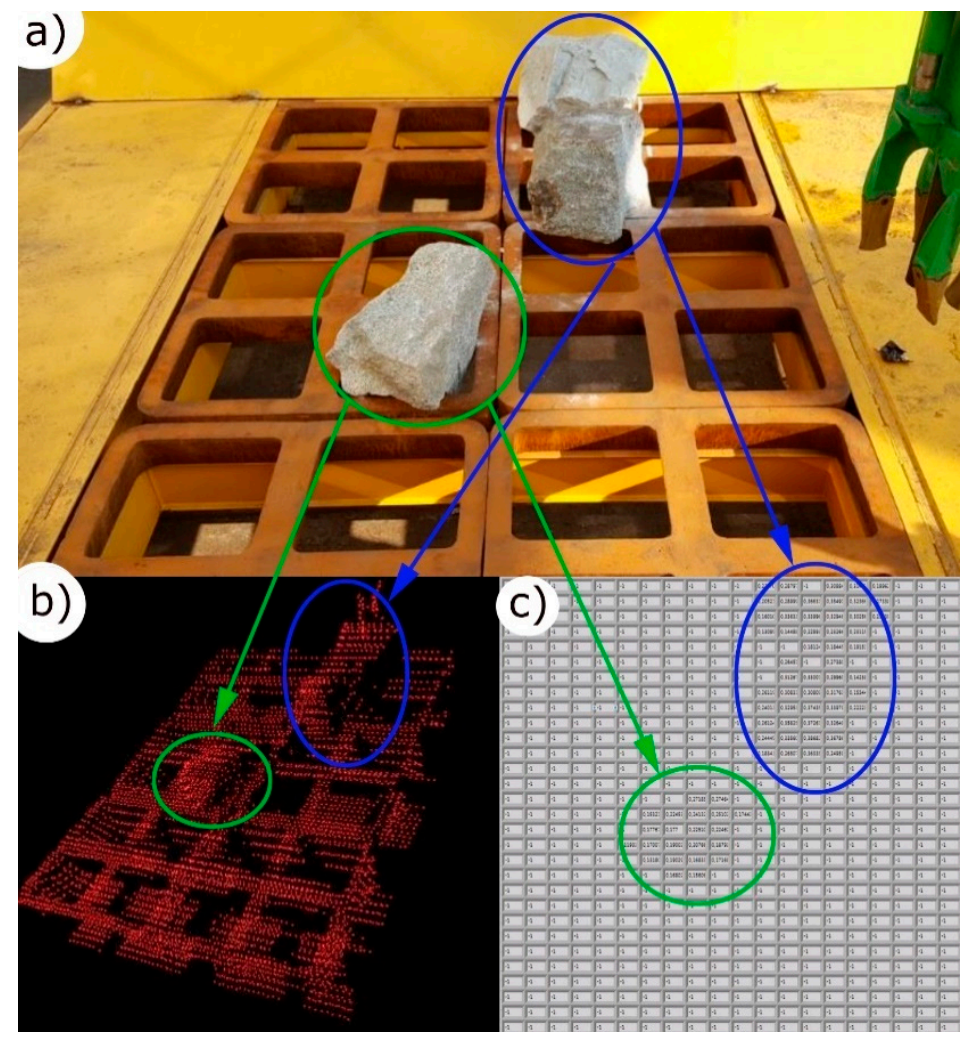

Figure 8. Analysis of the situation on the grate by the system: (a) view of mined rock on the grate; (b) view of the scan; (c) table of mined rock height on the grate [15].

This autonomous robot system for breaking rocks performs tasks in accordance with the assumptions. The systems of mined rock identification, trajectory determination and implementation work well. Research has shown that the system can clear the grate of large chunks of mined rock in a satisfactory manner [15]. The next step was to mount the system on a real grate in a mine. The works were completed successfully.

\subsection{Research Projects and Prototype Solutions}

Below we present some examples of projects and solutions that significantly contribute to increasing the level of mining robotization and pave the way for the future mine, which is to be fully robotic.

An interesting project has been implemented by the Space Research Centre of the Polish Academy of Sciences and the AGH University of Science and Technology - "Development of a model of an automatic core drilling rig for work in extreme conditions, in particular in the space environment." The aim of the project is to design, construct and test a model of an automatic core drilling rig, the task of which is the unmanned sampling of material from a depth of several meters. The expected operating environments of the machine are both hard-to-reach places on Earth as well as the surface of planets and asteroids. Specific requirements are related to available power and mass. In addition, work under vacuum causes difficulty. However, it can fill the market niche, especially in the context of Poland's accession to the European Space Agency [17].

Another interesting example of a project is the automation of the shaft support control and monitoring system. This solution was developed by the Central Mining Institute. The laser system of automatic geometry measurement has been tested in terms of the recording, visualization and signaling of emergencies. This system increases the operational safety of shaft equipment and allows for continuous supervision at lower costs than periodically performed classic geodetic measurements [18]. 
In the introduction, attention is drawn to threats occurring in underground mines, which are the main reason for interest in the robotics of mining works. However, the problem does not only concern regular, typical mining works, but also rescue operations. Robots equipped with sensors for measuring concentrations of dangerous gases and climatic conditions should also participate in rescue operations. Robots provide reconnaissance for rescue teams giving them advance information on the conditions prevailing in the excavation. Therefore, robots should ensure the greater safety of people. This necessity is recognized all over the world, as evidenced by the multitude of construction solutions of mining robots from various countries. Groundhog, Wolvarine V-2, Gemini-Scout robots developed in the US, Numbat and the Water Corporation robots constructed in Australia, or Telerescuer, implemented by an international consortium, are examples of some robots. Tangshan Kaicheng Electronic from China offers robots for the hard coal mining industry. As part of the project "Research and feasibility study of a model of the M1 category mobile inspection platform with electric drives for potentially explosive areas", implemented by the consortium of the Institute of Innovative Techniques EMAG and the Industrial Institute of Automation and Measurements PIAP, the Mobile Inspection Platform (MPI) was developed. The most important functionality of MPI is to measure the concentration and climate parameters of the mine atmosphere on a continuous basis or at the request of the operator. MPI also sends the measurement results to the control and measurement console. The measurement results are archived together with images from cameras operating in the visible and infrared band.

The MPI's place of operation is a potentially explosive zone. So, since the very beginning, the robot has been intended to work as a machine that meets the requirements of Directive 94/9/EC (ATEX), as well as the Machinery Directive 2006/42/EC (MD) and Directive 2004/108/EC(EMC). The robot has been designed to overcome various obstacles, such as debris, water, mud and mining floor railways [19]. The above-mentioned units have also developed the Mining Mobile Inspection Robot (GMRI) [20]. Figure 9 shows both MPI and GMRI mining inspection robots. These solutions are the first step for robots that will not only be able to reach casualties, but will also carry out basic activities related to the protection and removal of people from endangered areas.
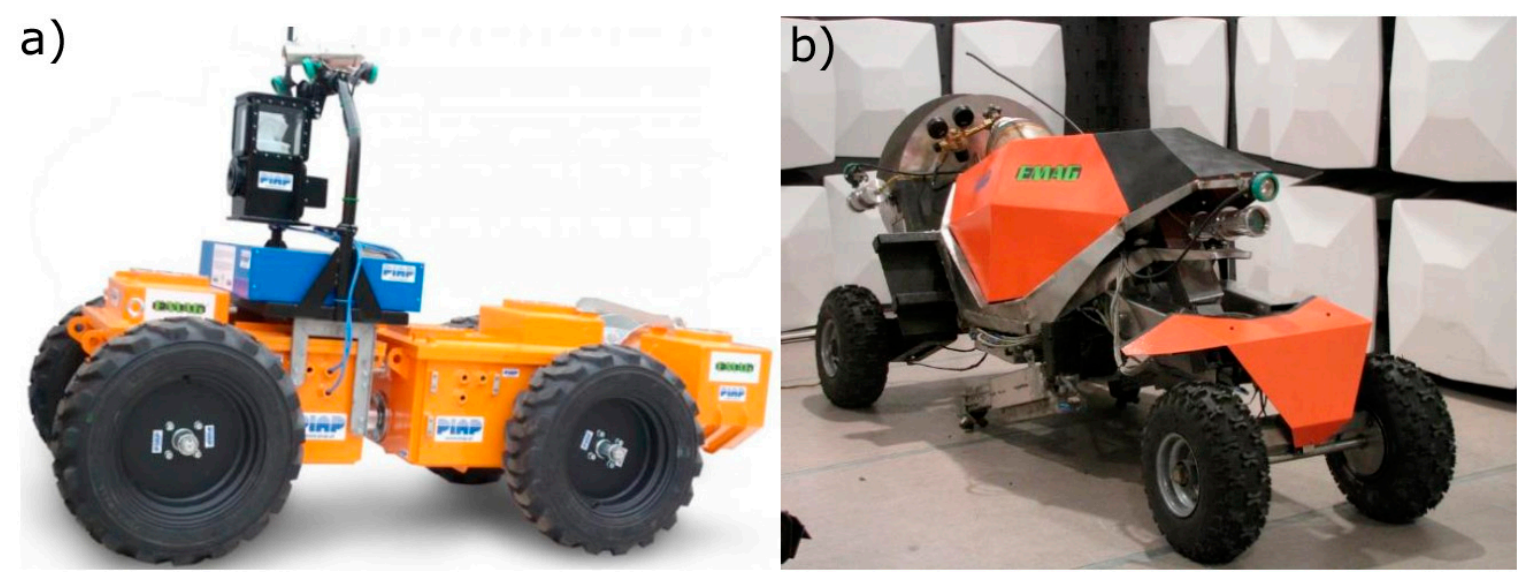

Figure 9. Mining inspection robots: (a) MPI [19], (b) GMRI [20].

\section{Activities Promoting Robotization in Mining}

Poland is actively engaged in the development of robotization in underground and surface mining as well as in solutions for underwater and space mining. In addition to the three selected initiatives described in Sections 4.1-4.3, meetings, symposia and conferences are organized in Poland. An important direction of the development of robotization is also the Polish consortium, EX-PL, as well as the Centre for Space Studies of the Kozminski University. 


\section{1. euRobotics Topic Group on Mining}

The well-known European association euRobotics has over 250 members. The aim of euRobotics is to increase European research, development and innovations in the field of robotics. euRobotics also supports its positive perception. The AGH University of Science and Technology leads the "Mining" group, one of 30 thematic groups in euRobotics. Thematic groups develop the content of the Strategic Research Agenda (SRA) and Multi-Annual Roadmap (MAR). Both SRA and MAR distributed by SPARC connects euRobotics with the European Commission in a public-private partnership. The SPARC partnership is the world's largest publicly funded robotics innovation program. Thematic groups (TG) identify the current challenges of their domain and describe the required progress in the capabilities of robots needed to meet these challenges. By connecting research, industry and end-users, TG can provide knowledge about the potential effects of robotics progress and enable knowledge transfer among the shareholders.

In 2014, AGH University of Science and Technology in Cracow took the initiative to create a new working group in the structures of the euRobotics association, in the field of mining (Robotics in Mining). The idea of this project was conceived during the First International MARG Conference. (MARG stands for Mechanizacja, Automatyzacja i Robotyzacja w Górnictwie). In March 2015, during the European Robotics Forum, TG Mining was officially appointed. The AGH University of Science and Technology in Cracow became its coordinator. A series of meetings for potential new members of the association and new members of TG Mining were organized in the first year. As a result of this activity, AGH in Cracow, as the coordinator, defined the Multi Annual Roadmap for mining for the coming years, which was submitted to the euRobotics association and, next, to the European Commission. In subsequent years, TG Mining members took part in conferences and forums organized in various places in Europe. Several European Robotics Forums (ERF) have taken place-ERF 2016 in Ljubljana, ERF 2017 in Edinburgh, ERF 2018 in Tamper and ERF 2019 in Bucharest. During ERF 2017, in some of these meetings, participants discussed the possibility of initiating cooperation between TG Mining and Construction Robotics, Nuclear Inspection, Inspection and Maintenance or Oil and Gas groups. However, this year's ERF 2020 meeting took place in March, in Malaga [21-23].

\subsection{Space Mining Conference}

In the middle of 2016, a team consisting of students and academic teachers enthusiastic about space exploration focused on the space industry. All its aspects related to mining were established at the AGH University of Science and Technology. Ideas for Space Mining Engineering (ISME) was created to prepare and conduct the Space Mining Conference organized by the AGH University of Science and Technology in Cracow. The first Student Space Mining Conference 2018 was a significant success and an important event. ISME organized a second conference in 2019. A third conference is being planned for 2020. The ISME Group (Krakow, Poland) covers all aspects (technological, mechanical, economic, legal and ethical) related to space exploration, including extra-terrestrial resource use. This initiative has attracted an increasing number of participants and listeners. Analyzing the speeches of the participants of these conferences, one can notice a great emphasis on the problems of automation and robotization of mining works as the only possibility of space exploitation. Although the topic is relatively new, it is rapidly developing. Current information can be found on the Conference website [24].

\subsection{PERASPER Research Cluster}

The PERASPERA project (in Latin "Per aspera ad astra" means "Through hardships to the stars"), created in 2014, is financed by the European Union under the Horizon 2020 program. The goal of the PERASPERA initiative is to support industry competence in Europe. The focus is planetary and orbital robotics, and to demonstrate key technologies related to these fields in space. In 2019, Poland joined the PERASPER Research Cluster. Poland's membership in the consortium may facilitate the participation 
of domestic space sector entities in innovative space projects and cooperation with large European entities, as well as the testing of technologies in the field of orbital and planetary robotics in space. Polish companies, institutes and universities have extensive experience in the field of ground robotics and implemented projects related to space robotics systems. The field of space robotics in which Poles have the widest competence is underground exploration. This exploration includes devices for sampling, mechanisms working in vacuums, devices for underground testing as well as systems and control sensors. Experience and potential in the production of subsystems and components for orbit robotics systems are also evident in Poland. Servicing objects in orbit can be accomplished because of expertise in Poland with gripping and holding mechanisms, control systems, connectors, motion sensors and antenna systems [25].

\section{Conclusions}

The underground mining industry has difficult conditions and high costs of implementation. The development of new technical measures is exposed to high risk in terms of both technical and financial capabilities of the contractor. Research and development (R\&D) entail the necessity to carry out basic tests in the first phase, including design works. The second phase of $R \& D$ involves carrying out field tests and implementing new machinery and equipment solutions. These tests need to be carried out under specific mining, geological, technical and organizational conditions. Tests must also comply with the regulations of the State Mining Authority (Poland) [26]. The existing solutions that have been used for many years in various industries cannot be easily transferred to underground mines. Robotic vehicles are currently able to respond to typical road situations, including pedestrians, traffic lights and traffic control by a police officer. However, underground loaders or dump trucks still do not have such autonomy. Moreover, typical anthropomorphic robotic solutions work well in the production process. These solutions include the implementation of assembly or welding processes, while the process of installing support arches in underground excavations has only been mechanized.

In mining, especially underground, the simplest solutions are the best. Difficult conditions and high costs sometimes limit the use of technical means to the necessary minimum. However, automation and robotization in mining are developing slowly and encounter many obstacles. Some solutions have already been implemented in mining practice. Solutions include systems supporting the work of self-propelled drilling carts and roadheaders, an autonomous machine for breaking rocks, automated longwall systems, and rescue works. The effects of implementing these solutions are tangible. The presented solutions make it possible to work in severe environment and conditions. People are not able to operate in these environments and conditions. For more specific effects, more research and analyses need to be conducted.

Poland has many underground mining plants and producers of mining machinery and equipment. Poland is good training ground for the development and testing of automated as well as robotic machines and machine systems. The establishment of TG Mining (part of euRobotics, a rapidly growing ISME group) organize space mining conferences. Other initiatives in Poland, like consortium EX-PL and the Centre for Space Studies of the Kozminski University, PERASPERA are also important for robotization.

Author Contributions: Both Ł.B. and W.B. collated the topics within this review and contributed to the writing of the text. Both authors have read and agreed to the published version of the manuscript.

Funding: This research received no external funding.

Acknowledgments: Acknowledgements to FAMUR S.A., Mine Master Sp. z o. o. and KGHM ZANAM S.A. for figures and materials.

Conflicts of Interest: The authors declare no conflict of interest. 


\section{References}

1. Semykina, I.; Grigoryev, A.; Gargayev, A.; Zavyalov, V. Unmanned Mine of the 21st Centuries. In Proceedings of the IInd International Innovative Mining Symposium (Devoted to Russian Federation Year of Environment), Kemerovo, Russia, 20-22 November 2017; EDP SCIENCES: Les Ulis, France, 2017; Volume 21.

2. Noort, D.; McCarthy, P. The Critical Path to Automated Underground Mining. In Proceedings of the First International Future Mining Conference and Exhibition, Sydney, Australia, 19-21 November 2008; Australasian Inst Mining \& Metallurgy: Carlton, Australia, 2008.

3. Jonak, J.; Gajewski, J. Mining machines robotization on the example of the heading machine. Transport. Przemysłowy i Maszyny Robocze 2011, 4, 66-69.

4. Biały, W. Determination of workloads in cutting head of longwall tumble heading machine. Manag. Syst. Prod. Eng. 2016, 1, 45-54. [CrossRef]

5. Bołoz, Ł. Unique project of single-cutting head longwall shearer used for thin coal seams exploitation. Arch. Min. Sci. 2013, 4, 1057-1070.

6. Bołoz, Ł. Longwall shearers for exploiting thin coal seams as well as thin and highly inclined coal seams. MIAG 2018, 2, 59-72.

7. Dziura, J. Mikrus system-New technology of low seams exploitation. Maszyny Górnicze 2012, 3, 3-11.

8. Famur, S.A. Available online: https://famur.com (accessed on 30 July 2020).

9. Mendyka, P.; Nawrocki, M.; Ostapow, L. Calibration of mining drilling rig boom equipped with feeder guiding system FGS. In Proceedings of the 14th International Conference Mechatronics Systems and Materials, Zakopane, Poland, 4-6 June 2018; Robak, G., Ed.; AIP Publishing LLC: College Park, MD, USA, 2018.

10. Mine Master. Available online: https://www.minemaster.eu/pl/pl (accessed on 30 July 2020).

11. Mendyka, P.; Kotwica, K.; Stopka, G.; Czajkowski, A.; Ostapów, L.; Karliński, J. Possibilities and Barriers in Implementation of Drilling Rig Remote Control. In Modern Technology and Safety in Mining; Kotwica, K., Ed.; Department of Mining, Dressing and Transporting Machines: Krakow, Poland, 2019; pp. 183-190.

12. Hasilová, K.; Gajewski, J. The use of kernel density estimates for classification of ripping tool wear. Tunn. Undergr. Space Technol. 2019, 88, 29-34. [CrossRef]

13. Jedliński, Ł.; Gajewski, J. Optimal selection of signal features in the diagnostics of mining head tools condition. Tunn. Undergr. Space Technol. 2019, 84, 451-460. [CrossRef]

14. Krauze, K.; Raczka, W.; Sibielak, M.; Konieczny, J.; Kubiak Culer, H.; Bajus, D. Automated transfer point URB/ZS-3. MIAG 2017, 2, 80-85. [CrossRef]

15. Krauze, K.; Rączka, W.; Konieczny, J.; Sibielak, M. Automatic ore loading point URB/ZS-3. CUPRUM 2016, 4, 5-11.

16. Sibielak, M.; Raczka, W.; Konieczny, J.; Kowal, J. Optimal control based on a modified quadratic performance index for systems disturbed by sinusoidal signals. Mech. Syst. Signal. Process. 2015, 64-65, 498-519. [CrossRef]

17. AGH w Krakowie. Available online: https://www.agh.edu.pl/nauka/info/article/kosmiczna-wiertnica (accessed on 30 July 2020).

18. Szade, A.; Szot, M.; Królak, M.; Urbańczyk, T. Multi-level intrinsically safe monitoring of the shafts' lining. Wiadomości Górnicze 2016, 7-8, 416-422.

19. Kasprzyczak, L.; Szwejkowski, P.; Cader, M. Robotics in mining exemplified by Mobile Inspection Platform. MIAG 2016, 2, 23-28.

20. Kasprzyczak, L.; Trenczek, S. Mining inspective mobile robot for monitoring hazardous explosive zones. Pomiary Automatyka Robotyka 2011, 2, 431-440.

21. Kasza, P. euRobotics-AGH koordynatorem Grupy Tematycznej: Górnictwo (TG Mining). In Proceedings of the MARG Conference Summary, Wisla, Poland, 17 June 2016.

22. Kasza, P. euRobotics-Way to the mining of the future. In Proceedings of the MARG Conference, Wisła, Poland, 26 June 2017.

23. Eurobotics. Available online: https://www.eu-robotics.net/eurobotics (accessed on 30 July 2020).

24. Konferencja Górnictwa Kosmicznego. Available online: www.kgk.agh.edu.pl (accessed on 30 July 2020). 
25. Urania-Postępy Astronomii Centrum Astronomii UMK. Available online: www.urania.edu.pl (accessed on 30 July 2020).

26. AGH. Available online: www.agh.edu.pl/nauka/info/article/macgyver-z-agh-czyli-prototyp-robotagorniczego (accessed on 30 July 2020).

Publisher's Note: MDPI stays neutral with regard to jurisdictional claims in published maps and institutional affiliations.

(C) 2020 by the authors. Licensee MDPI, Basel, Switzerland. This article is an open access article distributed under the terms and conditions of the Creative Commons Attribution (CC BY) license (http://creativecommons.org/licenses/by/4.0/). 